BULLETIN Bulletin hispanique

HispaniQuE Université Michel de Montaigne Bordeaux

123-2 | 2021

Investigaciones semánticas y léxicas actuales

\title{
Pilar Cagiao Vila (Coord.), Diplomacia y acción cultural americana en la España de Primo de Rivera
}

Madrid: Marcial Pons - Universidad Michoacana de San Nicolás de Hidalgo, 2020

Froilán Ramos Rodríguez

\section{(2) OpenEdition}

Journals

Edición electrónica

URL: https://journals.openedition.org/bulletinhispanique/14569

DOI: 10.4000/bulletinhispanique.14569

ISBN: 1775-3821

ISSN: 1775-3821

Editor

Presses universitaires de Bordeaux

Edición impresa

Fecha de publicación: 20 diciembre 2021

Paginación: 384-387

ISBN: 979-10-300-0-745-9

ISSN: 0007-4640

Referencia electrónica

Froilán Ramos Rodríguez, «Pilar Cagiao Vila (Coord.), Diplomacia y acción cultural americana en la España de Primo de Rivera», Bulletin hispanique [En línea], 123-2 | 2021, Publicado el 20 diciembre 2021, consultado el 07 febrero 2022. URL: http://journals.openedition.org/bulletinhispanique/14569 ; DOI: https://doi.org/10.4000/bulletinhispanique.14569

Este documento fue generado automáticamente el 7 febrero 2022.

Tous droits réservés 


\title{
Pilar Cagiao Vila (Coord.), Diplomacia y acción cultural americana en la España de Primo de Rivera
}

\author{
Madrid: Marcial Pons - Universidad Michoacana de San Nicolás de
}

Hidalgo, 2020

Froilán Ramos Rodríguez

\section{REFERENCIA}

Pilar Cagiao Vila (Coord.), Diplomacia y acción cultural americana en la España de Primo de Rivera. Madrid: Marcial Pons - Universidad Michoacana de San Nicolás de Hidalgo, 2020, 222 p. ISBN: 978-84-9123-891-1.

1 España y América han tenido, tienen y, posiblemente, seguirán teniendo una relación especial. El cruce del Atlántico, hace más de cinco siglos, trajo consigo la españolización de América y también la americanización de España, en diversos órdenes, desde el idioma y la gastronomía hasta el ADN entrelazado. Hoy una nueva colección de estudios académicos revisita esta multidimensionalidad hispanoamericana a partir de la diplomacia y la cultura durante el gobierno de Miguel Primo de Rivera (1923-1930), y el complejo cúmulo de intereses interconectados entre los Estados de la península y los del continente occidental.

2 A primera instancia, la atención y el número de investigaciones que suscitan las relaciones entre España y América indican la vigencia del tema como problema histórico, pero también la diversificación de los campos y áreas de interés. Precisamente, en este orden, el libro coordinado por la doctora Pilar Cagiao Vila ofrece nuevos enfoques de la temática, al reunir nueve trabajos de especialistas, que abordan la Exposición Iberoamericana de Sevilla de 1929 como epicentro para analizar los esfuerzos diplomáticos y las acciones culturales de uno y otro lado del océano, a través de estudios de casos concretos y de revisiones al interior de la España de la época. 
3 La parte inicial de la obra entrega distintas visiones de algunos de los países americanos, que se dieron cita en la exposición sevillana, entre ellos, Perú, Uruguay, Cuba, y Estados Unidos, además, del contexto de postguerra; Europa intentando dejar atrás la Gran Guerra, los primeros pasos de la Sociedad de Naciones en Ginebra, la irrupción de la dictadura del general Primo de Rivera y su agenda diplomática orientada a recuperar influencia española en América por medio de la promoción del hispanismo, al tiempo que los Estados Unidos afianzaba su presencia en hemisferio con el impulso del panamericanismo.

4 En este sentido, la catedrática Ascensión Martínez Riaza, de la Universidad Complutense de Madrid, examina los intereses diplomáticos del presidente peruano Augusto B. Leguía (1919-1930) en su ensayo titulado "Entre intenciones y realidades. El Perú en la Exposición Iberoamericana de Sevilla". Para Martínez, la acción cultural peruana fue "muy limitada", reservada a los actos protocolares y a los discursos oficiales hispanistas, coincidentes del oncenio y el primorriverismo. Además, apunta la autora, tampoco hubo coordinación diplomática ni colaboración efectiva entre el ministro plenipotenciario, Eduardo S. Leguía, y el cónsul en Sevilla, Guillermo Shaw, tanto para contrarrestar la presencia de Chile en la Exposición como en su misión para promocionar a Perú en la Madre Patria.

5 Seguidamente, la profesora Pilar Cagiao Vila, Universidad de Santiago de Compostela, analiza la presencia y labor uruguaya durante el encuentro internacional a través de su capítulo: "Condicionantes políticos y juego de la diplomacia. El Uruguay en la Exposición Iberoamericana de Sevilla (1923-1930)". En el mismo, la historiadora sostiene que el país rioplatense siguió una dinámica particular, al sumar, por un lado, una temprana disposición de adhesión a la comunión hispanista, desde comienzos de la centuria y lo largo de los años veinte, mientras que, por otro lado, la cercanía y trasfondo organizativo del campeonato mundial de fútbol de 1930, demandaron un esfuerzo especial a la banda oriental de río de la Plata. Con todo ello, Uruguay logró llevarse laureles de reconocimientos literarios, por ejemplo en Carlos Reyles, y la admiración por el aviador Tydeo Larre Borges y su vuelo trasatlántico.

6 Más tarde, la historiadora Ruxandra Guillama Camba, Universidad de Vigo, comparte su estudio "Pretextos para un encuentro entre Machado y Primo de Rivera. La Exposición Iberoamericana de Sevilla: Una mirada desde la prensa cubana", en el que los medios isleños, como el Diario de la Marina, demuestran las cercanías entre Gerardo Machado (1925-1933) de Cuba y Primo de Rivera, ambos de origen militar, pero la afinidad hispanista trascendía lo personal a los vínculos con la última colonia americana. En particular, la muestra cubana en Sevilla contó con el trabajo articular del embajador Mario García Kohly, jefe de la Legación en Madrid y declarado prohispanista.

7 Por su parte, Palmira Vélez Jiménez, académica de la Universidad de Zaragoza, titula su contribución: "La Exposición Iberoamericana de Sevilla de 1929 y la Implicación de Estados Unidos”. En ella, la autora discurre sobre el contexto de transformación de la época, entre fines del siglo XIX e inicios del XX, marcados por un doble proceso o recorrido paralelo: el avance de la influencia estadounidense como potencia en el continente y a nivel internacional tras la Primera Guerra Mundial, y también el creciente interés por los estudios sobre España, Hispanoamérica y lo español en las principales universidades de la costa este, a través de la adquisición de colecciones, bibliotecas, creación de cátedras y publicaciones. 
8 De la mano de lo anterior, la presencia de Estados Unidos en la cita iberoamericana resultaba especial. Así, el trabajo de Rosario Márquez Macías, de la Universidad de Huelva, titulado "Los Huntington en la España de 1929. Una crónica a través de la correspondencia privada", contribuye a comprender el papel desempeñado tanto por diplomáticos como por particulares estadounidenses. La historiadora reconstruye el itinerario del filántropo estadounidense Archer M. Huntington (1870-1955) y su esposa Anna durante su visita a Sevilla entre marzo y mayo de 1929. Huntington fue el fundador de la Hispanic Society of America en 1904, y había conocido España en sus varios viajes $(1892,1896,1898,1912,1918)$. Por ello la autora aporta una visión íntima a partir de las cartas del matrimonio, en las que se recogen sus impresiones personales de la España de su tiempo, los reconocimientos de los que fueron objeto, su encuentro con el príncipe Alfonso (1907-1938), y sus redes de contactos y amigos en el país.

9 La segunda parte de la obra está dedicada a examinar las diferentes acciones y las expectativas despertadas al interior de España en torno a la exposición de la capital andaluza. De esta manera, María Nieves Verdugo Álvez, de la Universidad de Huelva, intitula su trabajo "Asociacionismo y propaganda. La Sociedad Colombina y la participación de Huelva en la Exposición Iberoamericana de Sevilla de 1929". La autora discierne el rol competitivo de los distintos agentes por espacios de protagonismo en el encuentro iberoamericano, para ello profundiza competencia por ser la ciudad sede del evento, entre las ciudades históricas americanistas, Sevilla y Cádiz, y Huelva y los Lugares Colombinos, como La Rábida o Palos de la Frontera. Además, de la cruzada labor publicitaria que llevaron a cabo figuras tales como Juan Marchena Colombo, presidente de la Sociedad Colombina Onubense, Eustaquio Jiménez, o la arqueóloga inglesa Ellen M. Whishaw.

En esta línea, el profesor Juan Luis Carrellán Ruiz, de la Universidad de Huelva, comparte su análisis "La Exposición Iberoamericana de Sevilla de 1929 a través del órgano de difusión de la Unión Ibero-Americana: La Revista de las Españas". El catedrático evidencia documentalmente el especial interés de la asociación americanista (fundada en 1885), y de su principal órgano divulgativo, por la cita sevillana. Los distintos artículos referidos al encuentro, siguieron con detalle las inauguraciones de cada pabellón nacional, la presencia de las personalidades y de los avances de la época: lo develan la voluntad y carácter intelectual de acercamiento cultural de España y Portugal con las naciones americanas.

11 Por su lado, Philip D. Webb, Universidad de Santiago de Compostela, se adentra en la intensa labor diplomática de Paraguay detrás de la exposición sevillana, con su trabajo “Pueblos hermanos y Madre Patria. Juan O'Leary y los consulados paraguayos en España ante la cuestión del Chaco (1925-1934)". El capítulo profundiza en el esfuerzo organizativo del poeta e historiador Juan O'Leary, responsable de la Legación en Madrid entre 1925 y 1929, que logró articular tres metas importantes para el país suramericano: mejorar el desempeño de los cónsules en las ciudades españolas, una campaña propagandística en torno al Chaco Boreal, y adquisiciones armamentísticas para la preparación del ejército paraguayo.

12 Finalmente, Manuel Andrés García, Universidad de Huelva, cierra el recorrido del libro, con su ensayo "Manuel Ugarte y el americanismo catalán a través de sus colaboraciones en la Revista Comercial Ibero-Americana Mercurio". En el mismo, se exponen las "Crónicas Interoceánicas" publicadas por Ugarte en la revista catalana, con su mirada de un 
americanismo condicionado por su visión política de izquierda, y enmarcado en un discurso antiestadounidense.

13 La Exposición Iberoamericana de Sevilla (1929-1930) representó un hito importante en las relaciones culturales y de hermandad entre España y Portugal y los países americanos, que luego de casi una centuria no ha tenido una réplica del mismo tenor y voluntad. En ese sentido, este libro aporta otras perspectivas, diversas y equilibradas, que integran múltiples partes de un mismo todo, con imágenes globales y fuentes históricas originales, para comprender mejor el hecho y las ideas de su época.

14 En sus manos, los lectores acuciosos cuentan con un libro fluido, de lenguaje ameno y de miradas renovadas, que brinda la oportunidad de profundizar de manera crítica y documentada en las distintas formas interrelación iberoamericana, en la diplomacia paralela y las acciones culturales, pero también en la aproximación a las diferentes acepciones del americanismo y el hispanismo, que parecieran, a la vez, caminar de la mano de cada sociedad y de la sensibilidad su tiempo.

\section{AUTORES}

\section{FROILÁN RAMOS RODRÍGUEZ}

Universidad Católica de la Santísima Concepción (UCSC) 